\title{
Social Networks That Promote Well-Being Among Latino Migrant Day Laborers
}

\author{
Nalini Junko Negi \\ Lynn Michalopoulos \\ Javier Boyas \\ Adrianna Overdorff
}

\begin{abstract}
Latino migrant day laborers are a transnational population that often travels back and forth between borders in search of economic opportunities. These Latino day laborers (LDLs) are often at risk for exploitation and workers' rights abuses. Despite LDLs' heightened social vulnerability and risks, this population often does not access formal social or public health services due to their undocumented legal status, lack of health insurance and distrust of governmental social services. In light of LDLs' lack of access to formal services, social networks may enhance and protect their well-being and health through the exchange of emotional and social support, as well as the provision of concrete and practical services. Utilizing Berkman, Glass, Brissette, and Seeman's (2000) conceptual framework on social networks and health, this ethnographic study investigates the role of social networks in facilitating the well-being of LDLs $(N=150)$. Implications for social services for this transnational population are also discussed.
\end{abstract}

Keywords: Day laborers, Latino migrants, social services, transnational migrants

Globalization has led to a paradigmatic shift whereby many migrants live and work on both sides of the border in a transnational space that heightens their political and economic vulnerability (Sassen, 2002). In the United States, meeting the social service and public health needs of the approximately 11.2 million undocumented immigrants, with the largest group coming from Mexico (Pew Hispanic Center, 2011), has been challenging. While some data suggests that most immigrants are healthier when compared to U.S. born populations (Warner et al., 2006), emergent studies indicate a high risk sub-population comprised of mainly single, young, Latino transmigrant men. These men often work in the informal economy as day laborers and travel back and forth between borders in search of economic opportunities. These Latino day laborers (LDLs) are employed in construction or demolition work and are at risk for exploitation and workers' rights abuses, such as wage theft and dangerous working conditions (Quesada, 2008; Negi, 2011). Their vulnerability is heightened due to their undocumented immigration status. As a result, this population is considered to be easily deportable and sometimes beyond the protection of the law (Taran, 2001). Preliminary studies suggest that this population experiences a myriad of psychosocial vulnerabilities such as social isolation, family disruption, poverty, undocumented immigration status, and criminal victimization (Cepeda et al., 2012; Organista, 2007). The transient nature of this

\footnotetext{
Nalini Junko Negi, MSW, Ph.D., is an Assistant Professor in the School of Social Work at the University of Maryland in Baltimore; Lynn Michalopoulos is an Assistant Professor in the School of Social Work at Columbia University in New York; Javier Boyas is an Assistant Professor in the Department of Family Studies and Social Work at Miami University in Oxford, Ohio; and Adrianna Overdorff works for the Evergreen Health CO-OP in Baltimore, Maryland.
} 
population and an unstable residential base to provide comfort and social support can further exacerbate the risk factors that this population experiences (Valdez, Cepeda, Negi, \& Kaplan, 2010). Despite such heightened social vulnerability and risks, LDLs experience many barriers to care and often do not access formal social or public health services (Hargrove, 2006). Specifically, their undocumented legal status, lack of health insurance, and distrust of governmental social services are significant barriers to obtaining those services (Berk \& Schur, 2001). This is especially compelling as difficult life circumstances, which include discrimination and stress, can place this group at risk for mental health problems, which may be compounded by a lack of access to formal treatment (Moradi \& Risco, 2006). In light of the lack of access to formal services to address psychosocial needs, social networks may enhance and protect LDLs' well-being and health through the exchange of emotional and social support, as well as through the provision of concrete and practical services. Previous literature on African-Americans and Caribbean Blacks has indicated that social networks can play a protective role by reducing some of the negative consequences associated with a lack of professional social services (Woodward et al., 2008). Similarly, research on Latino immigrants indicates that social networks are positively associated with individual health and community growth (Garcia, 2005). However, little is known whether such a positive relationship exists among transnational migrant populations such as LDLs.

This qualitative study utilizes Berkman, Glass, Brissette, and Seeman's (2000) conceptual framework on social networks and health to investigate the role of social networks in facilitating the well-being of LDLs. In particular, this study elucidates participant-identified networks of support as well as provides rich contextual detail regarding how these networks may be leveraged to promote the welfare of this marginalized population.

\section{Literature Review}

Day labor work typically involves open-ended verbal contracts that are often negotiated on public street corners where day laborers congregate to look for work (Valenzuela, 2003). LDLs' public visibility, coupled with a lack of knowledge about this population often cause misconceptions from community members and law enforcement. LDLs are often seen as troublemakers, criminals, and loiterers (Quesada, 2008; Turnovsky, 2006), and as a result, their life struggles, including their mental health and social service needs, remain largely unknown to local officials or service providers in the United States (Turnovsky, 2004). A growing body of research indicates that rural Latino farmworkers, a demographically similar population to LDLs, experience social isolation and poverty, impacting well-being and creating increased risks for depression, anxiety, and substance abuse (Hovey \& Magana, 2000; Denner, Organista, Dupree, \& Thrush, 2005). Studies further indicate that various protective factors, including social support may facilitate the well-being of Latino farmworkers (Hovey \& Magana, 2000, 2002). The sparse literature on LDLs indicates that this population of urban-based immigrant workers experiences psychosocial problems similar to rural Latino farmworkers (Organista, 2007). However, the problems of day laborers may be compounded by the dangerous and unique conditions associated with their work as well as the broader urban 
environment in which they work and live. In light of such sociopolitical and psychosocial vulnerability, as well as lack of access to medical coverage, LDLs' social networks may act as a buffer to protect their well-being. This study uses a strengths focus to illuminate participant-identified social networks that enable well-being among LDLs.

\section{Social Networks and Health: Conceptual Framework}

Berkman et al.'s (2000) conceptual model of social networks asserts that broad social structural conditions (such as discrimination, poverty and undocumented immigration status) influence the development and nature of social networks, which in turn leads to individual pathways that combine to impact health. This framework suggests that social networks influence behavior through four health related pathways: social support, social influence, social engagement, and access to resources and material goods (Berkman et al., 2000). These networks are embedded within larger social and cultural contexts, which, in turn, have both a direct and indirect effect on the formation of a network (Berkman \& Glass, 2000). These social networks are comprised of both strong and weak ties (Granovetter, 1973; 1981). Strong ties consist of small, tight, and mostly homogenous networks that, while instrumental in providing social support, often do not connect LDLs to a wider range of people and resources outside the main network (McPherson, SmithLovin, \& Cook, 2001). Weak ties, in contrast, are heterogeneous and provide wider access to diverse resources, and thereby act as bridges to new sources of opportunities (Granovetter, 1981; Smith, 2000). Thus, the development of weak ties can be more critical in connecting marginalized populations, such as LDLs, with higher status contacts (Lin, Ensel, \& Vaughn, 1981).

Within the context of LDLs' lives, an understanding of these pathways may be particularly salient due to the under-utilization of formal social and public health services of this group. Such information can lead to the elucidation of potential modifiable protective factors with implications for the development of strategies to close the gap in service access and delivery among this population. To this end, this study utilizes Berkman et al.'s (2000) social networks and health conceptual framework to qualitatively examine the role and impact of social networks on the well-being of LDLs. In particular, this study explores the unique work and life context of LDLs in shaping the types of social networks they develop and how these networks impact the well-being of this population.

\section{Methods}

\section{Sample and Procedure}

This ethnographic study used participant observation, informal interviews, and two focus groups to explore the social networks of LDLs in a large city in the Southwest of the United States. Data used in this study is part of a larger mixed-methods study on factors associated with the psychological distress of day laborers with methods reported in detail elsewhere (Negi, 2011, 2013). Based upon extensive field work, the three largest and busiest day labor sites in a large city in the Southwest were selected. Over a two-year

period, and on a weekly basis, multiple researchers observed and recorded verbatim 
accounts, interactions, and informal interviews at the selected day labor corners to study the lived experiences of LDLs. Extensive field notes were recorded following each field visit to document the daily activities of the day labor corner including negotiation of work and payment, pick-ups by employers, and LDL interactions with each other and others. The informal interviews consisted of discussions regarding the participants' work, family and country of origin, and life stressors. Informal interviews included over 150 participants.

Two focus groups were also conducted at a nearby Mexican restaurant, often frequented by LDLs. The taquería was relatively private and allowed participants to exit quickly if a potential employer was approaching. A moderator guide, developed by the Principal Investigator (PI), employed open-ended questions to explore how participants manage and define well-being within their work and life contexts. The focus group was facilitated by the PI and a research assistant who took extensive notes on the process. Eleven respondents, between the ages of 30 and 60, were asked to discuss the meaning of well-being (bienestar) within the context of day labor work and the challenges experienced that may impact the mental health of this group. The participants were also asked to provide general strategies that they or others they know have used to deal with any work or life challenges.

\section{Data Analysis}

Thematic analysis was utilized to examine ethnographic and focus group data. This technique allows researchers to find common themes across participants without losing individual meanings and experiences (Creswell, 2007). The PI and a research assistant conducted a line-by-line analysis, read the transcripts of the data separately, and recorded any thoughts. Next, the PI and research assistant worked separately to group phrases that addressed the same topic area and created categories from these groups. Themes were taken from each of these categories and those that were not initially identified by both researchers were discussed thoroughly until agreement was reached on whether to include or omit a theme in the analysis. Initially, four themes reflecting the social networks of participants emerged during the coding process. Specifically, the initial emergent themes were: networks on day labor corners, peer networks, family networks, and networks with employers (patrones). The themes peer networks and family networks were collapsed into one, based upon extensive discussion that concluded that these networks were conceptually too similar to stand on their own. Furthermore, two themes (heightened vulnerability and barriers to accessing existing public services) were elucidated to establish the context whereupon the above mentioned social networks developed. Upon reaching consensus, each researcher independently coded the data. The researchers then met to discuss their thematic coding and to reach further consensus on coding. A third party auditor who was familiar with the data was invited to contribute in the four instances that consensus was not reached, and a consensual decision was made based upon this input. The use of multiple researchers minimized researcher subjectivity and maximized the internal validity of the data (McMillan \& Schumacher, 1997). The results are presented by first contextualizing the vulnerability of LDLs and their perceived barriers to formal social services and authorities. Next, the informal networks 
used by LDLs to facilitate well-being are identified as those within the day labor corner, peer and family, employers, and church members. The following results are presented through the triangulation of the ethnographic field notes recorded at the day labor corners. They include observations and informal interviews as well as quotes from the focus groups.

\section{Results}

\section{Contextualizing Vulnerability and Service Utilization Among LDLs}

Heightened vulnerability. Findings indicate that LDLs experienced a variety of psychosocial stressors such as criminal victimization, workers' rights abuses, and poverty due to their undocumented immigrant status and employment in the informal economy. Specifically, the informal verbal employment contracts with patrones (employers), their cash earnings, and distrust and fear of police or other authorities heightened their vulnerability to workers' rights abuses and other types of crime. Field notes from an informal interview with a 19-year-old Mexican migrant day laborer document the perilous conditions that LDLs must navigate due to their cash earnings:

He has been assaulted six or seven times while he has been living here... He says that he has been assaulted by Chicano (Mexican American, born in the US) gangs because they know that they (the workers) carry cash on them. I noticed that one of his eyes looked red - so I asked him what happened there - and he told me that he had just had been mugged the day before yesterday. He told me that he has never reported these muggings to the police.

In addition to violent victimization, a majority of the LDLs also reported experiencing wage theft or unpaid wages for work rendered by employers. This wage theft had a significant impact on the economic well-being of LDLs, as indicated in the following field note:

The worker told us that he had "lost" about \$300 last month and at that point had decided to not do anything about it. But now he is having a hard time paying his rent and wants that money to be recovered.

Without a formal work contract combined with their fear of deportation by police, many LDLs expressed feeling helpless and without much recourse. Consequently, wage theft had a negative psychological impact. One LDL, whose former employer owed him $\$ 600$ in wages, stated:

I feel fearful when I look for work now since they did not pay me the last time. What is the point of working if I am not going to get paid for all my efforts?

Barriers to accessing existing public services. As indicated above, the LDLs in this study indicated that they did not report crime as they were afraid of the police and feared that the police would not take their concerns seriously because they (LDLs) were sin papeles, or undocumented. In addition, many workers expressed that their sole purpose for being in the United States was to earn money to support their family in their country of origin. To this end, they did not want to risk exposure and deportation and jeopardize 
the flow of financial support. Participants also indicated that they knew that the city (where this study was conducted) was a "sanctuary city" (a city where the police do not enforce immigration laws or ask people about their immigration status); however, they still felt distrustful of police. This was especially true as the LDLs in this study reported adversarial experiences with the police. For example, many participants reported feeling harassed by police officers that asked them to leave the public street corners where they congregated to look for work. One worker stated, "They say that we are loiterers but we are here only (to support)... our family.”

Robbery and wage theft also served to exacerbate the poverty that most LDLs experienced. While most participants reported living in houses or apartments with multiple roommates, a minority of participants reported being homeless. These homeless LDLs indicated they had accessed shelter services provided by the city. However, they reported that the homeless shelters lacked bilingual services, and, as a result many did not feel comfortable continuing to use shelter services. One homeless immigrant participant stated that he chose to live on the streets with other Latino workers, rather than at a homeless shelter, as he felt more camaraderie and comfort on the streets with fellow workers than at the city-run shelter. Furthermore, while a majority of participants reported experiencing wage theft, many did not access advocacy organizations that were available to assist with wage recovery. The LDLs in this study that did not access advocacy organizations indicated that they had accepted the fact that they needed to afrentar la realidad, or "face the reality" of their difficult life and work conditions.

A majority of the participants indicated that they preferred soliciting work on public street corners despite the several city-run worker centers opened to discourage public solicitation of work. These worker centers aimed to reduce the tension between the city's need for labor and community opposition to street corners where day laborers congregated to look for work. When asked why they did not attend the worker centers, LDLs stated several reasons, including: location, lack of transportation (the centers were often located in areas that were either too far or not on the bus route where many of the workers lived), and the perceived unfair nature of the current "lottery" system of allocating employment opportunities to workers (which means that workers arriving at different times of the day had the same chance of procuring a job as those who arrived early). Finally, the LDLs in this study felt that not many employers knew about or used the worker centers to look for potential employees and that they were better off on street corners. Workers also stated that they had some hesitation attending worker centers because they did not want to be confused with panhandlers or perceived ex-convicts who they perceived were also looking for employment at the worker centers. They further indicated a preference for the flexibility and informality of the day labor corner versus the worker center and its associated rules. One participant voiced the workers' dislike of the institutional feel of the centers: "Everyone is sitting in a line. They look like sardines!"

\section{The Role of Social Networks}

The LDLs in this study indicated that they used their social networks to facilitate their well-being in light of their distrust of the police and lack of service use. In 
particular, networks developed at the day labor corner, with peers and family, with employers, and at church were considered to be the most salient to their well-being.

Building camaraderie at the day labor corner. Many social networks were developed at the corner while LDLs waited for work. In fact, some participants indicated that they would even come to the day labor corner on their day off to escape feeling lonely and to be with their peers. Field notes describe the day labor corner as a dynamic space where workers shared experiences and camaraderie:

The corner all of a sudden felt electrified by energy, as they haggled and negotiated for both work and the number of workers. The camioneta (pickup truck) took off with the two men, and the remaining men walked back to uswith chagrined smiles on their faces. Men who had not been interacting with each other were now sharing their feelings of frustration with others.

Participants indicated that the day labor corner was a space where workers would organize themselves against employers who were known to exploit workers. Specifically, participant observation indicated that LDLs would often warn other workers about exploitative employers or those who were known not to pay workers by yelling “ $i n o$ paga, no paga!” (doesn't pay, doesn't pay!) when the employer stopped his car at the day labor corner to look for employees. In this way, the day laborers organized themselves to prevent newer immigrant workers, as well as others, from being victimized by wage theft from known unscrupulous employers.

Peer and family networks. Peers and family were reported to provide practical and financial support through shared links to employment and local resources, including help paying rent and utilities. Most LDLs reported that they immigrated to the United States alone to support family members in their country of origin and spoke of the importance of tapping into peer networks to find roommates to ease the financial burden of rent and utilities. When new in a city, peer networks were also identified as essential in locating day labor corners to look for work, finding neighborhoods to live in and identifying resources such as restaurants and shops that cater to Latinos. Furthermore, peers also assisted in easing communication with family members. One LDL reported that he knew a truck driver who, when driving to Mexico, would transport his video letters to his wife and daughters, and return their video reply to him. Similarly, other workers reported that peers who traveled back to their country of origin helped by transporting letters, remittances, and general information.

Overall, many participants indicated that relationships with peers were significant. As one worker stated, "those that know more people...do better." However, there was also recognition that some peer networks could lead them to negative life choices or vicios (vices) such as, heavy drinking, substance use, fights, and solicitation of sex work, especially for younger day laborers. One focus group participant stated, "Younger people have fewer responsibilities for their families." While another added, "There is no one or nothing that controls them, but as they get older they realize the reality of things (increased responsibility towards family members).” 
For participants that had family in the United States, many indicated that they specifically immigrated to a particular place because they had a family member there. In a way, similar to peer networks, family members provided practical informal support such as help in becoming familiar with the area, and finding housing and work.

Building mutuality of trust with patrones. A mutual relationship of trust with employers (patrones) was viewed as paramount to ensure consistent work. Participants' indicated that their decision to migrate regionally was often influenced not only by the availability of work, but also trust in their employer. Field notes indicate one worker's description of the importance of mutual trust in his decision to migrate for employment, and how other social networks were deployed when work conditions were no longer optimal:

His brother met a patrón [in Los Angeles] who was very nice and he started working for him pretty regularly. After the job was over the brother's patrón said that he had other jobs available, not in Los Angeles, but in Fort Worth, TX. His brother was hesitant because it is a big risk to trust someone so much and move this way. But the patrón said that he could stay with him and that he would send him an airline ticket and all. So he told his brother to take the risk. His brother went to Fort Worth and he liked it a lot. He then asked him to come over as well as another brother from Mexico. They all worked there [in Fort Worth] fine but then the patrón died. Once the partner took over - things were not the same. The new patrón was not as nice and made their lives difficult. His brother then decided to leave since he heard that a city in the South West had some jobs...they all moved there and have been there for 2 years now.

Several participants discussed the importance of building relationships with the patrones as a way of ensuring consistent work. Specifically, participants discussed how being perceived as a good worker by a patrón was important as it would guarantee longer contracts of employment and lead to being sought out for future employment opportunities. In these instances, the patrón would call the LDL directly on his mobile phone to negotiate the terms of work; thereby, bypassing the competition present at the day labor corner. This was seen as very important as day labor work is highly inconsistent and often solicited on a daily basis.

Support through church. Participants who attended church often reported having more social ties and social support than those who did not. In particular, participants stated that church members tend to be united in their support for one another by offering help in times of emotional or financial need. Participants also identified the positive impact of increased church attendance on social networks, which improved one's chances of obtaining employment opportunities through personal referrals. During a focus group, one participant stated, "The most religious have the most amount of work" while another participant concurred, “...they (church members) help each other out.” Religion was important because it offered spiritual comfort and provided the opportunity to develop increased social networks that could provide social and emotional support, hence serving as a source of social capital. 


\section{Discussion}

This study advances the literature on Latino migrant day laborers by exploring the potentially protective role of social networks in maintaining the well-being of this marginalized and transmigrant population in the United States. This study also extends the use of Berkman et al.'s (2000) conceptual model on social networks and health by applying this theoretical framework to LDLs. This is especially relevant as LDLs have low levels of service utilization and this study's identification of salient social networks and their influence on the health of LDLs has implications for the development of strengths-focused programming with this under-served population. To this end, we first discuss how LDLs' structural conditions influenced the development of their social networks and how these networks impacted the health related behavior of this population. Next, we discuss how LDLs' social networks can be leveraged as sources of existing strengths to promote the well-being of this population, which has implications for practice and policy development. We conclude with an acknowledgement of study limitations as well as recommendations for future research.

Findings indicate that the structural conditions that LDLs face, including their undocumented immigration status, poverty, and employment in the informal market as day laborers had a distinct impact on the types of social networks they developed in the United States. These social conditions placed LDLs at a heightened vulnerability as many distrusted the police and other authorities and organizations to maintain their well-being. Like other migrant groups, LDLs reported that they were not likely to seek services due to persistent fears of being reported to immigration officials (Hagan, Rodriguez, Capps, \& Kabiri, 2003). This fear of exposure existed despite the fact that the city where this study was conducted is a "sanctuary city." This indicates that punitive anti-immigrant policy initiatives, as well as rhetoric, have had a direct negative impact on the service utilization of LDLs. In cases where workers sought services, lack of cultural responsiveness created an additional barrier to continued use of services.

In alignment with Berkman et al.’s (2000) conceptual model on social networks and health, LDLs' social networks influenced their health related behavior through four pathways: social support, social influence, social engagement, and access to resources and material goods. In accordance with Granovetter's (1981) conceptualization of social networks, LDLs mainly discussed the "strong ties" that they established with each other that provided them social support, influence and engagement. The development of such homogenous and tight networks was largely due to LDLs' experiences of discrimination which led them to feel fearful or distrustful of establishing links outside of their group. In addition, LDLs' relayed the establishment of "weak ties" with employers or patrones and indicated that these networks were vital in connecting day laborers to work opportunities. (Granovetter, 1973; 1981). Specifically, LDLs' persistent feelings of insecurity, based on their undocumented immigration status and their increased risk for crime victimization, influenced this population's sense of camaraderie and social support at the day labor corners. The day labor corners became a space of social engagement where LDLs could escape loneliness, develop social bonds with other men experiencing similar work and life conditions, and unite to protect themselves from workers' rights abuses. The day labor corner became a site where LDLs organized themselves to exert social influence 
and thereby protect themselves from unscrupulous potential employers. This building of solidarity-based social action is especially compelling in light of LDLs distrust of the police and other formal authorities.

Fostering and forging social relationships with other workers at the day labor corner or at church allowed LDLs increased opportunities and access to various types of resources not possessed by them individually. Similarly, building lasting relationships with patrones was viewed as critical as it provided LDLs with potential work stabilityhighly prized due to the inconsistent nature of day labor work. Without access to formal safety nets, LDLs' social networks became critical in facilitating their economic, social and psychological well-being.

\section{Social Service Implications}

While findings indicate that LDLs often develop extensive social networks to ameliorate the difficult conditions of their lives, the service utilization gap experienced by this population must be closed to ensure their well-being and health. In particular, the current study's findings indicate that scarcity of Spanish speaking and culturally responsive programs are significant barriers to service use. Educational training programs as well as policies need to continue to respond to this increasing need for services in Spanish. In addition, to maximize service-utilization, it is highly recommended that LDLs be consulted in the development of any services or programming aimed to meet their needs. Such consultation with LDLs and respect for their life expertise may allow for rich data that may lead to the development of highly effective social service programming. The use of the existing strengths of this population in the development of social service programming is also highly recommended. Findings indicate that day labor corners served as a psychosocial space where social networks were developed for the LDLs. Similarly, Turnovsky's (2004) ethnographic study of day laborers in the East Coast revealed that despite significant hardships, day labor sites provided a space for LDLs to develop a sense of camaraderie and community. Social service providers can utilize this information to conduct outreach and provide on-site services at day labor corners. For example, the health care industry has begun to provide mobile medical and dental healthcare. Providing mobile services in a context where many feel safe (the day labor corner) could potentially increase access to services for this population that they would not otherwise receive.

\section{Limitations}

Although our study is one of few investigations that seek to understand social networks and well-being among LDLs, a number of limitations should be acknowledged. The limited sample size and use of a purposive theoretical sampling technique limits the representativeness and generalizability of the findings. However, this sampling method was considered appropriate since the aim of the current study was to offer a preliminary understanding of social networks that impact well-being. Additionally, the use of purposive theoretical sampling facilitated the selection of day labor corners and allowed for participant recruitment, as LDLs are a hard population to reach. Furthermore, the study represents a distinctive and understudied population-urban Latino day laborers- 
and the sample size is considered to be appropriate for qualitative analysis (Creswell, 2007). Additionally, this study could have been impacted by several threats to its internal validity. LDLs are a vulnerable population and participants may have been reluctant to discuss their psychological well-being with a researcher. This study employed several precautions to minimize the effects of social desirability. For example, significant time was spent building trust and rapport with this population so that they would feel more comfortable discussing difficult or taboo issues with interviewers. Valdez and Kaplan's (1999) methodological procedures to establish entry into "hidden" communities proved to be especially useful in building trust with this community. To further minimize social desirability, all interviews were conducted in spots distant from the earshot of other workers to ensure the confidentiality of participants' responses. Additionally, all interviews were conducted in Spanish, the LDLs' native language.

\section{Conclusion and Recommendations for Future Research}

Despite such limitations, we believe that our study sheds light on the experience of a rising sub-population of migrants in the United States which is part of a larger global phenomenon. This research can inform variable selection for future quantitative research on the social networks of LDLs. Furthermore, longitudinal studies with social network analysis are recommended to examine the substance use and other health behaviors of this under-served population. The significant marginalization of day laborers and their exposure to various psychosocial and political risk factors for well-being underscore the importance of increasing knowledge of this population to inform social service interventions and policies. However, it also reveals a highly resilient population that has

developed complex social networks to buffer their well-being in the absence of favorable social structural factors.

\section{References}

Berk, M. L., \& Schur, C. L. (2001). The effect of fear on access to care among undocumented Latino immigrants. Journal of Immigrant and Minority Health, 3(3), 151-156.

Berkman, L., \& Glass, T. (2000). Social integration, social networks, social support, and health. In L. Berkman \& I. Kawachi (Eds.), Social epidemiology (pp. 137-173). New York, NY: Oxford University Press.

Berkman, L. F., Glass, T., Brissette, I., \& Seeman, T.E. (2000). From social integration to health: Durkheim in the new millennium. Social Science and Medicine, 51(6), 843857.

Cepeda, A., Negi, N., Nowotny, K., Arango, J., Kaplan, C., \& Valdez, A. (2012). Social stressors, special vulnerabilities and violence victimization among Latino immigrant day laborers in post-Katrina New Orleans. In M. Zatz, C. Kubrin, \& R. Martinez (Eds.), Punishing immigrants: Policy, politics, and injustice (pp. 207-231). New York, NY: New York University Press. 
Creswell, J.W. (2007). Qualitative inquiry and research design: Choosing among five approaches. Thousand Oaks, CA: Sage Publications.

Denner, J., Organista, K. C., Dupree, J. D., \& Thrush, G. (2005). Predictors of HIV transmission among migrant and marginally housed Latinos. AIDS and Behavior, 9(2), 201-210.

Garcia, C. (2005). Buscando trabajo: Social networking among immigrants from Mexico to the United States. Hispanic Journal of the Social Sciences, 27(1), 3-22.

Granovetter, M. S. (1973). The strength of weak ties. American Sociological Review, 78(6), 1360-1380.

Granovetter, M. S. (1981). Toward a sociological theory of income difference. In I. Berg (Ed.), Sociological perspective on labor markets (pp. 11-47). New York, NY: Academic.

Hagan, J., Rodriguez, N., Capps, R., \& Kabiri, N. (2003). Effects of immigration reform on immigrants' access to health care. International Migration Review, 37(2), 444463.

Hargrove, P. (2006). Social work practice with Mexican clients: Service provision with illegal entrants to the United States. Journal of Emotional Abuse, 6(2), 61-76.

Hovey, J. D., \& Magana, C. G. (2000). Acculturative stress, anxiety, and depression among Mexican immigrant farmworkers in the Midwest United States. Journal of Immigrant Health, 2(3), 119-131.

Hovey, J. D., \& Magana, C. G. (2002). Cognitive, affective, and physiological expressions of anxiety symptomatology among Mexican migrant farmworkers: Predictors and generational differences. Community Mental Health Journal, 38(3), 223-237.

Lin, N., Ensel, W. M., \& Vaughn, J. C. (1981). Social resources and strength of ties: Structural factors in occupational status attainment. American Sociological Review, 46, 393-405.

McPherson, M., Smith-Lovin, L., \& Cook, J. M. (2001). Birds of a feather: Homophily in social networks. Annual Review of Sociology, 27, 415-444.

Moradi, B., \& Risco, C. (2006). Perceived discrimination experiences of and mental health of Latina/o American persons. Journal of Counseling Psychology, 53(4), 411421.

Negi, N. J. (2011). Identifying psychosocial stressors of well-being and factors related to substance use among Latino day laborers. Journal of Immigrant and Minority Health, 13(4), 748-755.

Negi, N. J. (2013). Battling discrimination and social isolation: Psychological distress among Latino day laborers. American Journal of Community Psychology, 51(1/2), 164-174. doi: 10.1007/s10464-012-9548-0. First published online: August 3, 2012. 
Organista, K. C. (2007). Towards a structural-environmental model of risk for HIV and problem drinking in Latino labor migrants: The case of day laborers. Journal of Ethnic and Cultural Diversity in Social Work, 16(1-2), 95-125.

Pew Hispanic Center. (2011). Unauthorized immigrant population: National and state trends, 2010. Retrieved from http://www.pewhispanic.org/files/reports/133.pdf

Quesada, J. (2008). From Central American warriors to San Francisco Latino day laborers: Suffering and exhaustion in a transnational context. Transforming Anthropology, 8(1-2), 162-185.

Sassen, S. (2002). Global cities and diasporic networks: Microsites in global civil society. In M. Glasius, M. Kador, \& A. Helmut (Eds.), Global civil society (pp. 217-238). Oxford, UK: Oxford University Press.

Smith, S. S. (2000). Mobilizing social resources: Race, ethnicity, and gender differences in social capital and persisting wage inequalities. The Sociological Quarterly, 41(4), 509-538.

Taran, P. A. (2001). Human rights of migrants: Challenges of the new decade. International Migration, 38(6), 7-51.

Turnovsky, C. P. (2004). Making the queue: Latino day laborers in New York's street corner labor markets (Working Paper No. 98). Retrieved from University of California website: http://escholarship.org/uc/item/2v21732m\#page-1

Turnovsky, C. P. (2006). A la parada: The social practices of men on a street corner. Social Text, 24(88), 55-72.

Valdez, A., Cepeda, A., Negi, N., \& Kaplan, C. (2010). Fumando la piedra: Emerging patterns of crack use among Latino immigrant day laborers in New Orleans. Journal of Immigrant and Minority Health, 12(5), 737-742.

Valdez, A., \& Kaplan, C. (1999). Reducing selection bias in the use of focus groups to investigate hidden populations: The case of Mexican American gang members from South Texas. Drugs and Society, 14(1-2), 209-224.

Valenzuela, A. (2003). Day labor work. Annual Review of Sociology, 29, 307-333.

Warner, L. A., Valdez, A., Vega, W. A., De la Rosa, M., Turner, R. J., \& Canino, G. (2006). Hispanic drug abuse in an evolving cultural context: An agenda for research. Drug Alcohol Dependence, 84(Suppl), S8-S16.

Woodward, A. T., Taylor, R. J., Bullard, K. M., Neighbors, H. W., Chatters, L. M., \& Jackson, J. S. (2008). The use of professional services and informal support among Black Americans with a mental disorder. Psychiatric Services, 59(11), 1292-1298.

\section{Author note:}

Address correspondence to Nalini Junko Negi, MSW, Ph.D., University of Maryland, Baltimore, School of Social Work, 525 W. Redwood Street, Baltimore, MD 21201.

Email: nnegi@ssw.umaryland.edu 